\title{
Cholinergic hyperactivity and negative symptoms: behavioral effects of physostigmine in normal controls ${ }^{1}$
}

\author{
Rajiv Tandon, John F. Greden and Roger F. Haskett \\ Department of Psychiatry, University of Michigan Medical Center, Ann Arbor, MI 48109, USA
}

(Received 20 August 1992; revision received 29 October 1992; accepted 5 November 1992)

Intravenous infusion of physostigmine (a centrally active anticholinesterase agent) in normal subjects leads to a syndrome of psychomotor inhibition; this has been proposed as a model for selected symptoms of depression. In view of its similarity to the negative schizophrenic syndrome, we compared the 'physostigmine syndrome' to the negative symptom profile by evaluating the behavioral effects of intravenous physostigmine infusion in seven normal volunteers. Observer ratings and self description revealed significant withdrawal, apathy, alogia, lethargy, decreased energy, slowed thoughts, diminished affective responsivity, and reduced hedonic capacity. Subjects did not report sadness, ideas of hopelessness, worthlessness, or guilt. These findings support the implication of cholinergic hyperactivity as one mechanism in the pathophysiology of negative schizophrenic symptoms.

Key words: Cholinergic; Physostigmine; Negative symptom; Depression; (Schizophrenia)

\section{INTRODUCTION}

Despite the renewed interest in the negative symptoms of schizophrenia (Strauss et al., 1974; Crow, 1980; Andreasen, 1982), their underlying pathophysiology remains obscure. Although a variety of structural, neurochemical, developmental, and other abnormalities have been implicated in the production of negative symptoms (Greden and Tandon, 1990), none of these hypotheses can be regarded as proven. We have recently suggested that cholinergic hyperactivity may be one mechanism involved in the production of negative schizophrenic symptoms (Tandon and Greden, 1989). We sought to evaluate this hypothesis by studying the behavioral effects of a cholinergic agent in

Correspondence to: R. Tandon, Schizophrenia Program, University of Michigan Medical Center, Ann Arbor, MI 48109-0120, USA.

${ }^{1}$ Presented in part at the annual meeting of the $\Lambda$ merican College of Neuropsychopharmacology (ACNP), San Juan, Puerto Rico, 1987. normal volunteers; the hypothesis would predict that these behavioral effects would resemble the negative symptom profile.

Intravenous infusion of physostigmine, a centrally active anticholinesterase agent, in normal controls leads to a behavioral syndrome characterized by withdrawal, lethargy, apathy and reduced energy, slowed thoughts, decreased thoughts, motor retardation and decreased monotonous speech (Modestin et al., 1973; Davis et al., 1976; Risch et al., 1981; Janowsky et al., 1986). In view of the similarity of these behavioral effects to selected clinical features of depression, these findings have been used to implicate cholinergic dysregulation in mood disorders (Janowsky et al., 1974; Risch et al., 1981; Dilsaver, 1986). Parallels between the physostigmine profile and the negative schizophrenic syndrome also appeared striking to us upon initial consideration. We conducted the present study in an attempt to examine in more detail the 'physostigmine syndrome' and to compare its resemblance to the negative schizophrenic syndrome. 


\section{METHODS}

Seven healthy male subjects between the ages of 21 and 45 were recruited by newspaper advertisements for participation in this study. We screened each individual by questionnaire, telephone, and personal interview, and selected only those without any personal or family history of psychiatric disorder. There was no history of substance abuse, and none of the participants suffered from any physical disorder or had taken any medications for at lcast the preceeding 2 weeks. All were familiarized with the study design and provided informed consent. Each subject received a compensation of $\$ 50.00$ for participation in the study. Neuroendocrine data from these infusions was reported previously (Carroll et al., 1980).

On the evening prior to the infusion, subjects were hospitalized at the Clinical Research Center at the University of Michigan Medical Center and an indwelling venous catheter was inserted. The following day, all subjects received $0.75-1.0 \mathrm{mg}$ intravenously of methscopolamine bromide, a peripheral cholinergic blocker without significant central effects. 'This drug was used to prevent peripheral cholinomimetic toxicity from physostigminc. This dose of methscopolamine promptly produced tachycardia in all subjects; the pulse rate was monitored and methscopalamine was readministered at doses of $0.1-0.2 \mathrm{mg}$ intravenously if cardiac rate decreased below $100 / \mathrm{min}$. We then infused 2-4 $\mathrm{mg}$ of physostigmine salicylate intravenously in $200 \mathrm{ml}$ of normal saline over a $40 \mathrm{~min}$ period. In this study, no systematic placebo control infusions were employed for comparison.

One of us (JFG) completed the Rater Activation-Inhibition Scale (Janowsky et al., 1973) at 15min intervals throughout the physostigmine infusion. Ratings were conducted in a single-blind manner; while the rater was not blinded, subjects were unaware of the timing of the infusion. The inhibition scale was developed by Janowsky et al. (1973) to evaluate the general 'anergic-inhibitory' effects of physostigmine and evaluates subjects on a scale of $0-5$ along the following dimensions: (1) irritable, (2) lethargic, (3) dysphoric, (4) slow thoughts, (5) wants to say nothing, (6) hostile, (7) withdrawn, (8) wants to be alone, (9) apathetic, (10) crying, (11) sad, (12) lacks energy, (13) sleepy,
(14) drained, (15) hypoactive, (16) lacks thoughts, (17) motor retardation, (18) psychotic, (19) angry, (20) emotionally withdrawn. Additionally, the following items are similarly scored and constitute the activation scale: (21) cheerful, (22) friendly, (23) interacting, (24) talkative. Scores on these 24 items were compared between the prephysostigmine phase and the point of maximal symptoms following physostigmine infusion, using the Student's paired $t$-test. Verbal observations made by subjects over the course of the study were transcribed; we then identified any statements reflecting cognition, mood, or psychomotor inhibition and activation. For comparisons with the negative schizophrenic syndrome, subscales from the Scale for the Assessment of Negative Symptoms (SANS, Andreasen, 1983) were utilized.

\section{RESULTS}

All subjects showed a similar response to the physostigmine infusion. After a brief mild anxiety state, usually described as 'nervousness', features of psychomotor retardation became evident about $20 \mathrm{~min}$ following the onset of infusion. Subjects described themselves as 'drained', became apathetic, experienced all their mental processes as 'slowed down', were reluctant to talk, and reported a paucity of ideas. These symptoms increased in intensity to a peak at about $30 \mathrm{~min}$ before reaching a plateau, and returned to baseline about $60-90$ min following onset of the infusion. Only three of our seven patients reported nausea, but not until after the peak of the observed behavioral changes.

Observer ratings on the following behavioral items increased significantly $(p<0.05)$ after physostigmine infusion: withdrawn; apathetic; lacks energy; drained; hypoactive; lethargic; motor retarded; slow thoughts; wants to say nothing; wants to be alone; sleepy; lacks thoughts; emotionally withdrawn. Ratings on the following items decreased significantly: interacting; talkative; cheerful. Ratings on the following items did not change significantly: irritable; hostile; crying; sad; psychotic; angry; friendly. This profile is strikingly consistent with that reported in prior physostigmine studies. None of the subjects reported sadness or depression, and none cried or admitted to 
irritability, nor did any express feelings of hopelessness, worthlessness, or guilt.

Both observer ratings and subject self-reports revealed that major components of the negative schizophrenic syndrome (affective flattening, alogia, avolition-apathy, and anhedonia) were present following physostigmine. On the other hand, distinctive depressive features (such as sadness, crying, guilt, etc.) were not noted.

\section{DISCUSSION}

The results of this study indicate that the behavioral effects of intravenous physostigmine closely resemble many of the features of the negative schizophrenic syndrome. Normal subjects became withdrawn, apathetic, hypoactive, lethargic, motor retarded, they desired to be alone, were emotionally detached, and had slowing of thoughts, speech, and motility; these features occurred in the absence of significant mood changes. In view of the absence of a control comparison group (no placebo infusions) and the single-blind study design, however, caution is warranted in the interpretation of these data.

The 'physostigmine syndrome' has been relatively well studied. The detailed studies by Janowsky et al. (1973, 1974, 1986) have been replicated by others (Modestin et al., 1973; Davis et al., 1976; Risch et al., 1981), and there is general agreement that the drug consistently induces withdrawal, apathy, and related symptoms in normal subjects. There is, however, some continued uncertainty about whether it may initiate legitimate depressive mood in normal individuals. One study (Risch et al., 1981) seems to suggest this, while another (Davis et al., 1976) agrees with our findings by failing to note any significant increases in depressive mood following the infusion. However, physostigmine is a somewhat 'dirty' drug pharmacologically with both muscarinic and nicotinic properties (and the nicotinic system can modulate monoaminergic and other neurotransmitter systems); consequently, interpretation of physostigmine effects in pure muscarinic cholinergic terms is flawed and limited.

The possible role of acetylcholine in schizophrenia is intriguing but sketchy and controversial
(Tandon and Greden, 1989; 1990). Results of various studies do little more than provide substantiation that the cholinergic system may be involved in 'some schizophrenic symptoms'. While some studies report brief beneficial effects of cholinomimetic agents in schizophrenia (Pfeiffer and Jenney, 1957; Rosenthal and Bigelow, 1973), others report a worsening of schizophrenic symptomatology (Rowntree et al., 1950). It should be noted that these evaluations of the cholinergic system in schizophrenia were conducted before investigators began categorizing schizophrenic symptoms specifically as 'positive' and 'negative'; modulation of the cholinergic system may have opposite effects on positive and negative symptoms (Tandon and Greden, 1989) and this may provide a partial explanation for the somewhat contradictory findings in previous studies of the cholinergic system in schizophrenia.

More recently, there have been suggestions that anticholinergic agents may antagonize some therapeutic effects of neuroleptics, with selective exacerbation of the cluster of positive psychotic symptoms but without any reported adverse effects on negative symptomatology (Johnstone et al., 1983; Singh et al., 1987). Other studies have highlighted the benefits of continued antiparkinsonian medication in chronic schizophrenic patients, and have noted increased subjective distress and 'depressive' symptomatology following their withdrawal (Manos et al., 1981; Jellinek et al., 1981). There also have been several case reports of schizophrenic patients abusing anticholinergic drugs, with most patients reporting mood-elevating, energizing, stimulating, and socializing effects of these agents (Fisch, 1987; Wells et al., 1989). We conducted a pilot study (Tandon et al., 1988) by administering $10 \mathrm{mg} /$ day trihexiphenidyl to five chronic schizophrenic patients with predominantly negative symptoms; these patients were stabilized on neuroleptic agents without extrapyramidal sideeffects or tardive dyskinesia. Improvement was noted in four of the five patients, as measured by the BPRS (Overall and Gorham, 1962) and the SANS (Andreasen, 1983), with significant amelioration noted in the areas of affective flattening, anhedonia-asociality, and avolition-apathy. In a recent study on the effects of biperiden (an anticholinergic agent) on positive and negative symptoms in thirty medication-free schizophrenic patients 
(Tandon et al., 1991a), we observed a significant decrease in negative symptom severity following biperiden.

There may be a pattern in these scattered reports: administration of an anticholinesterase to normal subjects may induce a clinical profile that resembles many of the key features associated with negative schizophrenia; cholinomimetic agents may intensify selected negative schizophrenic symptoms in patients with the syndrome; anticholinergic agents may relieve them; some schizophrenic patients may experience energizing, stimulating effects from anticholinergic drugs, and may thus 'abuse' them.

These checkered pieces of data suggest that cholinergic hyperactivity might be implicated in the pathogenesis of negative schizophrenic symptoms (Tandon and Greden, 1989; 1990). Although the evidence is preliminary and somewhat speculative, this prospect clearly warrants further investigation. This hypothesis is not incompatible with prior formulations that cholinergic hyperactivity may be implicated in the pathogenesis of affective dysregulation. Instead, it dramatizes the importance of considering phenomenology in study design, and not restricting ourselves to current nosological classification schemes. The mechanism of cholinergic overdrive may be involved in both the negative schizophrenic syndrome and certain aspects of the depressive syndrome; this may provide a partial explanation for the phenomenological similarity between these syndromes and the frequent difficulty in differentiating between them. The common mechanism of cholinergic hyperactivity may also serve to explain some similar neurobiological abnormalities in schizophrenia and major depression (Tandon et al., 1991a; Tandon et al., 1991b; Riemann et al., 1991; Tandon et al., 1992). In view of the converging suggestive evidence but somewhat speculative nature of the hypothesis, a systematic comparison of the role of the cholinergic system in the pathophysiology of schizophrenia and major depression is warranted.

\section{REFERENCES}

Andreasen, N.C. (1982) Negative symptoms in schizophrenia: definition and reliability. Arch. Gen. Psychiatry 39, 784-788.
Andreasen, N.C. (1983): Scale for the Assessment of Negative Symptoms (SANS). Iowa City, University of Iowa.

Carroll, B.J., Greden, J.F., Haskett, R.F., Feinherg, M., Albala, A.A., Martin, F.I.R., Rubin, R.T., Heath, B., Sharp, P.T., McLeod, W.L. and McLeod, M.F. (1980) Neurotransmitter studies of neuroendocrine pathology in depression. Acta Psychiatr. Scand. Suppl. 280, 183-199.

Crow, T.J. (1980) Molecular pathology of schizophrenia: more than one disease process? Br. Med. J. 280, 1-9.

Davis, K.L., Hollister L.E., Overall J., Johnson, A. and Train, K. (1976) Physostigmine: effects on cognition and affect in normal subjects. Psychopharmacology 51, 23-27.

Dilsaver, S.C. (1986) Cholinergic mechanisms in depression. Brain Res. Rev. 11, 285-316.

Fisch, R.Z. (1987) Trihexiphenidyl abuse: therapeutic implications for negative symptoms of schizophrenia. Acta Psychiatr. Scand. 75, 91-94.

Greden, J.F. and Tandon, R. (1990) Introduction. In Greden, J.F., Tandon, R. (Eds.) Negative Schizophrenic Symptoms: Pathophysiology and Clinical Implications. American Psychiatric Press, Washington DC, pp. xxv-xxix.

Janowsky, D.S., El-Yousef, M.K., Davis, J.M and Sekerke, J.H. (1973) Parasympathetic suppression of manic symptoms by physostigmine. Arch. Gen. Psychiatry 28, 542-547.

Janowsky, D.S., El-Yousef, M.K. and Davis, J.M. (1974) Acetylcholine and depression. Psychosom. Med. 36, 248-256.

Janowsky, D.S., Risch, S.C., Kennedy, B., Ziegler, M. and Huey, L. (1986) Central muscarinic effects on mood, cardiovascular function, pituitary and adrenal neuroendocrine release. Psychopharmacology 89, 150-154.

Jellinek, T., Gardos, G. and Cole, J.O. (1981) Adverse effects of antiparkinson drug withdrawal. Am. J. Psychiatry 138, 15671571

Johnstone, E.C., Crow, T.J., Ferrier, I.N., Frith, C.D., Owens, D.G.C., Bourne, R.C. and Gamble, S.J. (1983) Adverse effects of anticholinergic medication on positive schizophrenic symptoms. Psychol. Med. 1983; 13, 513-527.

Manos, N., Gkiouzepas, J., Tzotzoras, T. and Tzanetoglou (1981) Gradual withdrawal of antiparkinson medication in chronic schizophrenics: Any better than the abrupt? J. Nerv. Mental Dis. 169, 659-661.

Modestin, J., Hunger, J. and Schwartz, R.B. (1973) Uber die depressogene Wirkung von physostigmin. Arch. Psychiatrie Nervenkrankh. 218, 67-70.

Overall, J.E. and Gorham, D.R. (1962) The Brief Psychiatric Rating Scale. Psychiatric Reports 10, 799-812.

Pfeiffer, C.C. and Jenney, E.H. (1957) The inhibition of the conditioned response and the counteraction of schizophrenia by muscarinic stimulation of the brain. Ann. NY Acad. Sci. 66, 753-764.

Riemann, D., Gann, H., Fleckenstein, P., Hohagen, F., Olbrich, R. and Berger, M. (1991) Effect of RS-86 on REM latency in schizophrenia. Psychiatry Res. 38, 89-92.

Risch, S.C., Cohen, R.M., Janowsky, D.S.. Kalin. N.H., Sitaram, N., Gillin, J.C. and Murphy, D.L. (1981) Physostigmine induction of depressive symptomatology in normal human subjects. Psychiatry Res. 4, 89-94.

Rosenthal, R. and Bigelow, L.G. (1973) The effects of physostigmine in phenothiazine resistant chronic schizophrenic 
patients: preliminary observations. Compr. Psychiatry 14 , 489-494.

Rowntree, D.W., Nevin, S. and Wilson, A. (1950) The effects of diisopropylfluorophosphonate in schizophrenia and manic-depressive psychosis. J. Neurol. Neurosurg. Psychiatry $13,47-62$.

Singh, M.M., Kay, S.R. and Opler, L.A. (1987) Anticholinergic-neuroleptic antagonism in terms of positive and negative symptoms of schizophrenia: implications for psychobiological subtyping. Psychol. Med. 17, 37-48.

Strauss, J.S., Carpenter, W.T. Jr. and Bartko, J.J. (1974) Schizophrenic signs and symptoms. Schizophr. Bull. 1974; $4,61-69$.

Tandon, R. and Greden, J.F. (1989) Cholinergic hyperactivity and negative schizophrenic symptoms: a model of dopaminergic/cholinergic interactions in schizophrenia. Arch. Gen. Psychiatry 1989; 46, 745-753.

Tandon, R. and Greden, J.F. (1990) Cholinergic excess and the negative schizophrenic syndrome. In Negative Schizophrenic Symptoms: Pathophysiology and Clinical Implications. Greden, J.F., Tandon, R. (Eds.) American Psychiatric Press, Washington DC, pp. 99-111.
Tandon, R., Greden, J.F. and Silk, K.R. (1988) Treatment of negative schizophrenic symptoms with trihexiphenidyl. J. Clin. Psychopharmacol. 8, 212-215.

Tandon, R., Greden, J.F., Goodson, J., Shipley, J.E., Mann, N. and Eisner, W.H. (1991a) Muscarinic hyperactivity in schizophrenia: relationship to positive and negative symptoms. Schizophr. Res. 4, 23-30.

Tandon, R., Mazzara, C., DeQuardo, J.R., Craig, K.A., Meador-Woodrufr, J.H., Goldman, R. and Greden, J.F. (1991b) Dexamethasone suppression test in schizophrenia: relationship to symptomatology, ventricular enlargement, and outcome. Biol. Psychiatry 29, 953-964.

Tandon, R., Shipley, J.E., Taylor, S., Greden, J.F., Eiser, A., DeQuardo, J.R. and Goodson, J. (1992) Electroencephalographic sleep abnormalities in schizophrenia. Arch. Gen. Psychiatry 49, 185-194.

Wells, B.G., Marken, P.A., Rickman, L.A., Brown, C.S., Hamann, G. and Grimmig, J. (1989) Characterizing anticholinergic abuse in community mental health. J. Clin. Psychopharmacol. 9, 431-435. 